Artículos 



\section{LA DECADENCIA ESPAÑOLA \\ DEL SIGLO XVII: LA ESCUELA AUSTRIACA DE ECONOMÍA Y LA INTERPRETACIÓN DE LA CRISIS}

JAIME HERNÁN-PÉREZ AGUILERA*

Fecha de recepción: 30 de enero de 2014.

Fecha de aceptación: 25 de septiembre de 2014.

Resumen: La Decadencia Española del siglo XVII fue una crisis profunda, con unas consecuencias dramáticas para la población. Muchos autores consideran a los costes de la política imperial española, la defensa del monopolio comercial y de la fe católica, el conflicto permanente con Francia por la hegemonía en Europa, con Inglaterra por la defensa del monopolio americano o con el Imperio Otomano por el control del Mediterráneo, como las causas principales. Sin embargo, la expansión descontrolada de la masa monetaria debida a los metales preciosos procedentes de América, el recurso al crédito para financiar los gigantescos déficits públicos de la Monarquía Hispánica y las alteraciones monetarias, unidas al intervencionismo del gobierno ofrecen, desde la perspectiva que ofrece la Teoría Austriaca del Ciclo Económico, una nueva interpretación. Las políticas de austeridad, control del gasto público, reducción de la presión fiscal y reorganización del sistema monetario, emprendidas a finales del siglo XVII, estabilizaron la economía y permitieron regresar a una senda de crecimiento sostenido.

Palabras clave: Política Monetaria, Política Fiscal, Alteraciones Monetarias, Déficit Público, Intervencionismo Estatal, Recesión, Estanflación.

Clasificación JEL: E3, E4, E5, H3, H6, N1.

* Doctor en Economía por la Universidad Rey Juan Carlos. Licenciado en Económicas por la Universidad Complutense. Licenciado en Historia por la UNED. Diploma en Estudios Avanzados de Historia Moderna (DEA) por la UNED. Email: sercojaime@gmail.com 
Abstract: The Decline of the Spanish seventeenth century was a deep crisis, with dramatic consequences for the population. Many authors consider the costs of the Spanish imperial politics, defense and commercial monopoly of the Catholic faith, the continuing conflict with France for hegemony in Europe, with England for the defense of American monopoly or the Ottoman Empire for control Mediterranean, as the main causes. However, the uncontrolled expansion of the money supply due to the precious metals from America, the use of credit to finance the huge deficits of the Spanish Monarchy and monetary changes, coupled with government intervention offered, from the perspective offered Austrian Theory of Economic Cycle, a new interpretation. Austerity policies, control of public expenditure, reducing the tax burden and reorganization of the monetary system, initiated in the late seventeenth century, stabilized the economy and allowed to return to a path of sustained growth.

Key words: Monetary Policy, Fiscal Policy, Monetary Disturbances, Public Deficit, State Interventionism, Recession, Stagflation.

JEL Classification: E3, E4, E5, H3, H6, N1.

\section{I \\ INTRODUCCIÓN}

Cualquier fenómeno social es de una extraordinaria complejidad, como lo es explicar la Decadencia Española del siglo XVII. Con este artículo pretendemos dar una explicación sencilla para analizar las líneas generales del proceso de la Decadencia Española del siglo XVII desde una óptica propia de la Escuela Austriaca de Economía. Esta escuela considera que detrás de toda actividad económica y social se encuentra la acción humana, el individuo, y sus propios fines y deseos para alcanzar unos objetivos, para los que busca unos medios. Detrás de este axioma tan sencillo se encuentra una potente explicación de los procesos económicos y sociales, en los que la historia y la teoría económica juegan un papel imprescindible. En nuestro caso particular, para explicar una crisis tan profunda y duradera como fue la Decadencia Española del siglo XVII utilizaremos la Teoría Austriaca del Ciclo Económico (en adelante TACE). 
El contraste entre los primeros años del siglo XVI y los años finales del XVII no pueden ser más evidentes. A comienzos del siglo XVI España ocupaba una posición económica envidiable, con una industria castellana en crecimiento gracias al favorable comportamiento demográfico, al mercado americano y a la revolución de los precios que ya había comenzado, aunque levemente; las manufacturas castellanas disfrutaban de una época de producción y exportación elevadas, sobre todo hacia Francia e Inglaterra, y la agricultura evolucionaba favorablemente. Políticamente España era el centro del poder político y financiero mundial. Al finalizar el siglo XVII, España había perdido no solo ese poder político, sino cualquier atisbo de riqueza o prosperidad. Pero, ¿por qué se produce la Decadencia? ¿A qué se debe su intensidad y duración?

En el siglo XVII España sufrió una profunda crisis económica y política que los historiadores definen como Decadencia Española. Son muchos los factores que confluyeron en la misma, y muchos autores coinciden generalmente en considerar los costes de la política imperial española, la defensa del monopolio comercial, el compromiso con la defensa de la fe católica, el conflicto permanente con Francia por la hegemonía en Europa, con Inglaterra por la defensa del monopolio americano o con el Imperio Otomano por el control del Mediterráneo, como las causas más generales de la Decadencia, consecuencias que tuvieron un impacto económico por las necesidades de financiación que conllevaron, y cuyos recursos exigieron un coste a la economía que no podía afrontar. Los metales preciosos americanos, el recurso al crédito bancario y las alteraciones monetarias no fueron suficientes para financiar a la Monarquía Hispánica, pero tuvieron una consecuencia inmediata: la inflación.

En el caso español el proceso inflacionario se aceleró por la confluencia de estos tres acontecimientos, que afectaron a toda España en general, pero que fue particularmente duradera y notable en Castilla, dado que era el centro económico y financiero de la Monarquía. Estos tres mecanismos inflacionarios fueron:

- La llegada masiva de metales preciosos de América, primero de oro a medida que se iban descubriendo nuevos territorios, 
y después de plata. Todos estos recursos se utilizaron para financiar una política imperial cuyos costes consumían enormes cantidades de recursos. En realidad, las remesas americanas actuaban como una garantía frente a banqueros y acreedores, pero estas garantías no fueron suficientes para las necesidades de financiación de la Monarquía, por lo que se hizo necesario recurrir al crédito bancario.

- El creciente recurso al crédito de la banca para cubrir los ingentes déficits públicos. Banqueros alemanes en primer lugar, después genoveses y finalmente portugueses y españoles, todos acudieron solícitos a cubrir las necesidades de crédito de la Monarquía, dinero muchas veces creado artificialmente mediante el proceso bancario de reserva fraccionaria, estableciéndose una mutua relación de intereses políticos y económicos. Pero el volumen de crédito no fue suficiente para financiar a la Monarquía Hispánica, y fue necesario intervenir sobre el valor del dinero.

- Las alteraciones monetarias, que fueron especialmente dañinas para la economía productiva y comercial. La alteración del valor del dinero para obtener recursos, reduciendo la ley de las monedas o resellando el valor facial, acentuó la subida de precios y generó un fenómeno que traería de cabeza a las autoridades, como fue el premio de la plata.

Los tres mecanismos operaron prácticamente simultáneamente a lo largo de la primera mitad del siglo XVII, y provocaron un episodio muy intenso de inflación. Las remesas de metales preciosos expandieron la masa monetaria sin ningún control, pero al no ser suficientes para cubrir los gastos de la política que ejecutaba la Monarquía Hispánica, el Rey tuvo que recurrir al crédito bancario que le proporcionarían los banqueros y los hombres de negocios. Las garantías ofrecidas a los mismos fueron inicialmente las remesas de plata, pero al no cubrir éstas las obligaciones comenzarían las emisiones de grandes cantidades de títulos de deuda, los juros, que contribuyeron aún más a crear dinero adicional. Finalmente, ante la crítica necesidad de ingresos de la Hacienda Real, se procedió a manipular el valor del dinero, reduciendo la ley de las monedas o alterando su valor facial, lo que 
terminó por provocar un caos monetario, más inflación y sobre todo la pérdida de confianza en una institución clave para el cálculo económico y la cooperación social, como es el dinero.

En definitiva, la Decadencia Española del siglo XVII fue una crisis con una elevada inflación, conocida como Revolución de los Precios, altas tasas de paro y una destrucción del tejido productivo y comercial, sin duda acelerada ante las medidas que fue tomando el gobierno de la Monarquía Hispánica como reacción a las consecuencias tan negativas que manifestaba la crisis. Si hay una teoría que nos permite interpretar esta crisis es sin duda la Teoría Austriaca del Ciclo Económico (TACE).

II

LA TEORÍA DEL CICLO AUSTRIACO DE ECONOMÍA Y LA DECADENCIA ESPAÑOLA

De acuerdo a la TACE, los cambios monetarios jamás son neutrales. Cuando se crea una determinada cantidad de dinero, ésta entra en la economía de una manera precisa, se gasta en determinados bienes y servicios y después, lentamente se extiende al resto de la estructura productiva, pero tiene un efecto inesperado sobre determinados precios cuya alteración genera a su vez modificaciones en la asignación de recursos. A consecuencia de ello, los empresarios comienzan a invertir en procesos de negocio que antes no eran rentables, desplazando además mano de obra hacia estos sectores. Se crean nuevos negocios, muy intensivos en capital, pero sobre todo se alteran las etapas o estructuras de producción. Este incremento relativo de los gastos de inversión hace aumentar el precio de los factores productivos, adoptándose métodos de producción menos intensivos en trabajo, lo que hace aumentar la demanda de recursos naturales. Esto provoca a las industrias de bienes de consumo una reducción de sus beneficios, favoreciendo todo ello un trasvase de factores productivos y en definitiva una alteración de la estructura productiva capitalista.

Pero esta situación no es duradera en el tiempo. Pronto, la demanda de bienes de consumo comienza a aumentar al haber mayor renta percibida, especialmente por los trabajadores que 
han sido desplazados a los nuevos sectores y que disponen de nuevo dinero y de nuevas posibilidades de crédito. Además, la alteración en las etapas de producción ha provocado un alargamiento de las mismas, de manera que la oferta disponible de bienes de consumo es menor, lo que presiona más sobre los precios. Este aumento de precios favorece el alza de los beneficios de las industrias del consumo en detrimento de los sectores de bienes de inversión así, de nuevo se produce un traslado de factores de producción de la inversión al consumo, generando pérdidas a los sectores más capitalistas como la construcción, los astilleros, etc. Comienzan a cerrar empresas y a fracasar los proyectos empresariales que de otra manera no habrían tenido lugar al no ser rentables. Se generaliza primero la crisis y después la depresión, que se manifiesta por un exceso de capacidad, un aumentando el paro y el cierre de los proyectos empresariales, es la hora del necesario ajuste.

Para verificar nuestra hipótesis de partida y comprobar si los tres efectos originaron la Decadencia Española, vamos a estudiar los procesos y hechos económicos que intervinieron a lo largo de los siglos XVI y XVII, utilizando para ello la TACE. Para ello utilizaremos los datos recogidos en el trabajo efectuado por Earl. J. Hamilton, en concreto El tesoro americano y la revolución de los precios en España 1501-1650, una obra imprescindible para conocer el proceso inflacionario que comenzó en España, pero que se extendió al resto de Europa.

III

\section{LAS REMESAS DE METALES PRECIOSOS}

El descubrimiento de América generó una coyuntura crítica favorable a la Monarquía Hispánica al ofrecer una independencia financiera al rey de la que carecían el resto de monarcas europeos. Este poder financiero derivó en un enorme poder político, capaz de doblegar a las Cortes de Castilla y de competir con los diferentes países de su entorno europeo por la defensa de sus territorios y sus monopolios comerciales, pero también otorgó un poder económico indiscutible al monarca. 
Para garantizar esa independencia financiera la Corona, en línea con el pensamiento económico de la época, estableció un monopolio comercial exclusivo y creó la Casa de Contratación para controlar a efectos fiscales los ingresos de metales preciosos procedentes de América, ya que le correspondían la quinta parte de los mismos, es decir, el llamado «quinto real». Según los datos calculados por Hamilton en la Casa de Contratación, entre 1503 y 1640 se realizaron unas importaciones totales de $16.886 .807 \mathrm{Kg}$ de plata y $181.227 \mathrm{Kg}$ de oro. Por otra parte, Renate Pieper ${ }^{1}$ calcula que la cantidad de dinero que se introduce a través de remesas en el periodo comprendido entre 1500-1640 fue de 188,03 millones de ducados. Entre 1500-1550 el volumen de dinero en España aumentaría de 5 a 17 millones de ducados, entre 1550-1600 se quintuplicó hasta alcanzar los 91 millones de ducados, y finalmente en el periodo 1600-1640 la cantidad se volvió a duplicar hasta alcanzar los 188 millones de ducados ya citados. Todo ello tuvo un efecto similar a una bajada de los tipos de interés que efectúan hoy en día los Bancos Centrales, y como bien apuntó Mises:

No son solo los gobiernos los que mediante la emisión de papel moneda, provocan cambios en la relación monetaria. Incrementar la producción de los metales preciosos que se emplean como dinero provoca efectos similares, si bien en este caso posiblemente no sean los mismos sectores de la población los respectivamente beneficiados y perjudicados.»²

Esta expansión artificial de la cantidad de dinero y la masiva liquidez provocó, como ya hemos apuntado en nuestro análisis del ciclo económico austriaco, una descoordinación en la estructura intertemporal del proceso productivo y un desajuste en las preferencias de consumo de los individuos. Las remesas de plata convirtieron millones de kilogramos de plata en monedas que circulaban por la economía nacional, muchas de ellas como garantía de préstamos bancarios solicitados por la monarquía para

1 R. Pieper, La Revolución de los Precios en España 1500-1640: sus causas y sus efectos, Anexo Tabla III, p. 111.

2 L. von Mises, La acción humana, cap. 17, p. 497. 


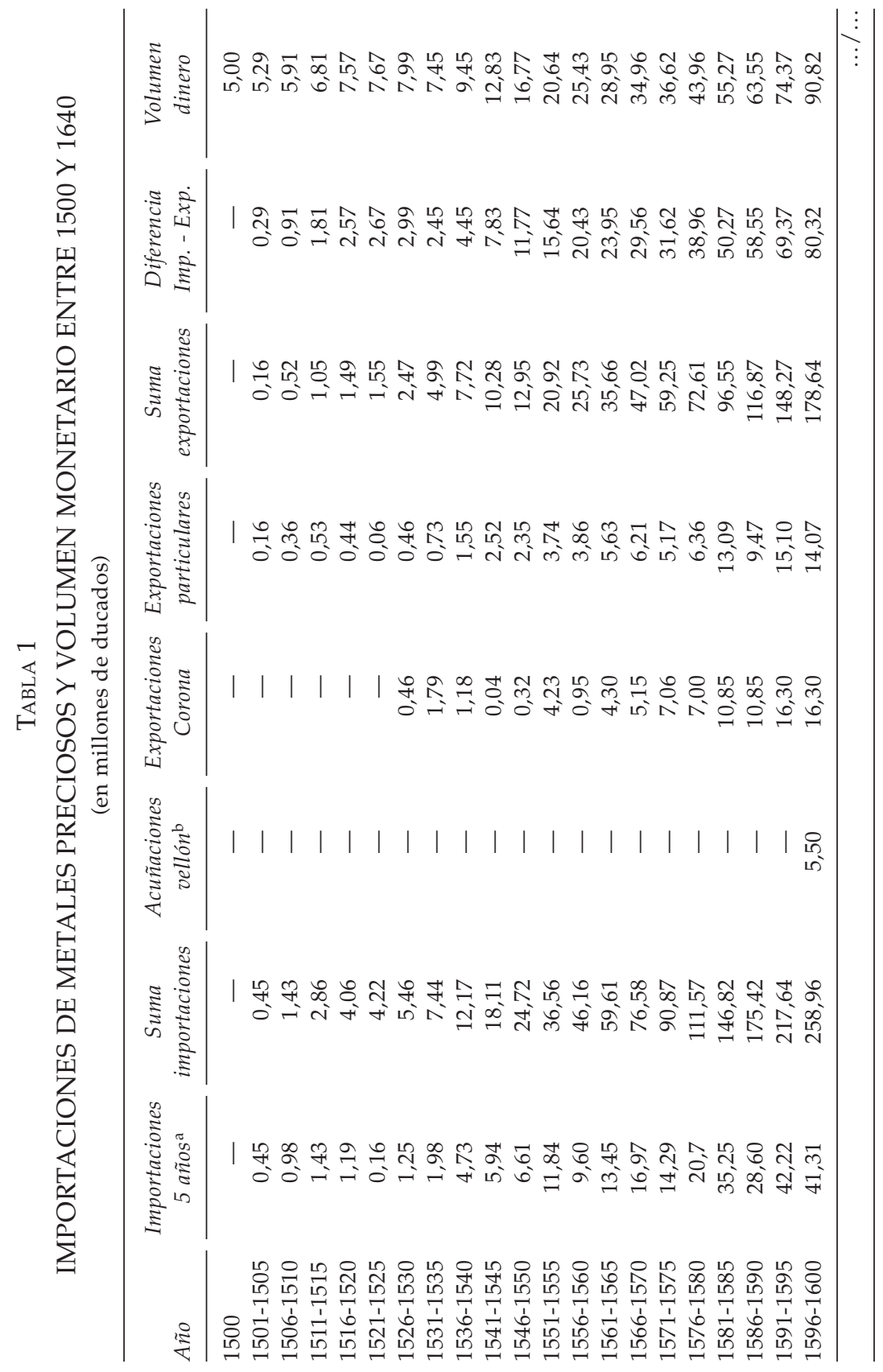




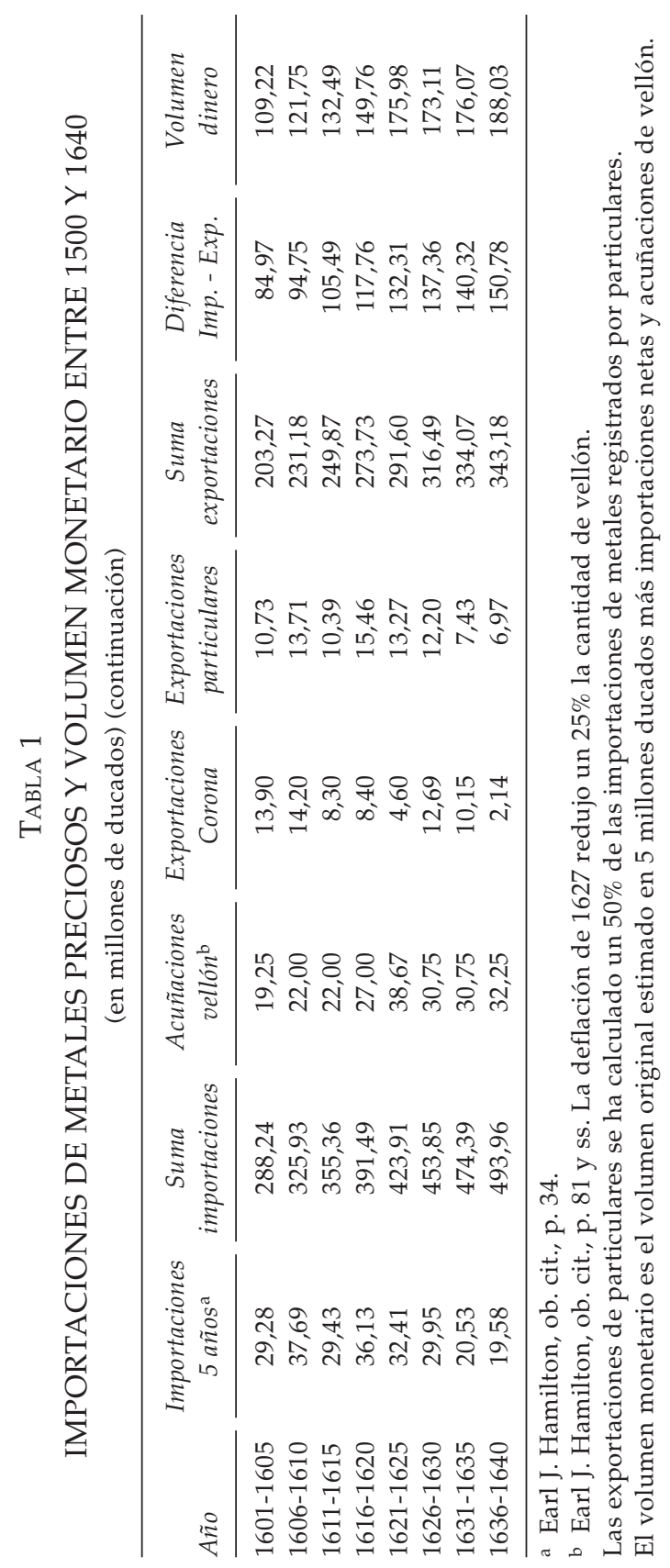


financiar su crónico déficit público. A consecuencia de ello, las bases para la Decadencia estaban sentadas, al desatar un proceso inflacionario que desajustó por completo el sistema de precios y que obligó a intervenir aún más a la monarquía sobre la actividad económica, agravando las consecuencias del periodo de crisis, que coincide con la Decadencia de España en el siglo XVII.

\section{IV \\ EL RECURSO AL CRÉDITO DE LA MONARQUÍA HISPÁNICA}

A la expansión monetaria que se llevó a cabo a través de las remesas americanas, habría que añadir otra no menos importante, como era la generación artificial de crédito a partir de la actividad bancaria con reserva fraccionaria. El desarrollo de los grandes estados europeos, España, Francia e Inglaterra, y de su estructura de poder en torno a la monarquía absoluta, discurre en paralelo con el crecimiento de la banca y la disponibilidad de crédito para mantener a las crecientes burocracias estatales, las Casas Reales y todo su aparato económico y de propaganda política, así como para financiar las políticas imperiales adoptadas por cada país. En el caso particular de la Monarquía Hispánica, los reyes de la Dinastía Austria utilizaron con verdadera profusión a los hombres de negocios, a los banqueros, para obtener crédito sobre el que apoyar el ejercicio de su política, ya que los recursos económicos, obtenidos sobre la base de una economía de subsistencia y una sociedad estamental, no eran suficientes para financiarla. Si hacemos una similitud con la situación que experimentaban las monarquías europeas en el siglo XVII, de absoluta dependencia del crédito, Hayek explicó en su obra Los fundamentos de la libertad ${ }^{3}$

\footnotetext{
${ }^{3}$ Hayek en su obra Los fundamentos de la libertad analiza los factores que determinan el progreso de la civilización, las instituciones que se han desarrollado para asegurar la libertad individual y su aplicación práctica a situaciones de crisis sociales y políticas contemporáneas. La segunda parte del libro, Libertad y Ley, en el capítulo IX trata de La coacción y el Estado, donde trata aspectos que bien se pueden extrapolar a la Monarquía Hispánica de los siglos XVI y XVII. F. von Hayek, Los fundamentos de la libertad, Unión Editorial, Madrid, 2008.
} 
que el crédito creado tenía una motivación política y usó el argumento de la elección pública (Public Choice) para explicar los beneficios políticos de expandir el crédito antes de unas elecciones. Las monarquías absolutas no necesitaban recurrir a unas elecciones, pero supieron aprovecharse del crédito que ofrecía la banca y los banqueros; a cambio, obtuvieron cuantiosos beneficios económicos así como privilegios, una relación de complicidad que permitió a la Monarquía Hispánica obtener más recursos sobre los que apoyar su política imperial, a costa de romper el sistema económico y productivo.

El rey, por medio del Consejo de Hacienda, solicitaba créditos o asientos a los hombres de negocios. Los asientos eran los contratos que fijaban las condiciones del crédito, que contenían dos clases de privilegios más allá de las condiciones financieras, como eran las adehalas o recompensas otorgadas a los asentistas por efectuar los préstamos, y las facultades o permisos especiales que les otorgaba la Corona, siendo la más importante la licencia de saca, para poder exportar dinero. Incluso en las consignaciones, es decir, los pagos que hacía la Hacienda Real de los créditos establecidos, se fijaban privilegios, entre ellos el principal de todos, la satisfacción de las deudas en moneda de plata. Esta relación entre Monarquía y financieros constata un hecho evidente ya en pleno siglo XVII, la complicidad entre banca y finanzas de la Monarquía, porque como bien apunta el profesor Huerta de Soto:

Los banqueros fueron violando los principios tradicionales del derecho en el depósito irregular, así como las razones por las cuales los mecanismos sociales de control no pusieron coto a los abusos cometidos. Éstos (...) casi desde el principio respaldaron la actividad irregular de los banqueros y les concedieron exenciones y privilegios a cambio de poder aprovecharse de la misma para sus propios fines. Se explica así el surgimiento de las tradicionales relaciones de complicidad y solidaridad entre las instituciones estatales y las bancarias y que se han mantenido hasta hoy. ${ }^{4}$

En el siglo XVII los banqueros entraron a formar parte del poder político de diversas maneras. Uno de los cargos políticos

${ }^{4}$ J. Huerta de Soto, Dinero, crédito bancario y ciclos económicos, p. 35. 
preferidos era la posesión de ayuntamientos, de regimientos. El regimiento era el máximo órgano municipal y era donde se decidían los cargos y oficios concejiles, pero sobre todo, donde se realizaba el control y supervisión de las cuentas. Numerosos hombres de negocios como Gaspar y Baltasar de Paredes en Valladolid, los Cortizos en Madrid, Ventura Donis en Valladolid o Sebastián Siliceo en Badajoz, accedieron a estos cargos, para hacer credencial de tener estatuto de nobleza o hidalguía, pero sobre todo, por la gestión de los impuestos del Servicio Ordinario y Extraordinario, así como de la administración del Servicio de Millones. La presencia de banqueros en el poder fue completa con su acceso al Consejo de Hacienda, dentro de los diferentes organismos del Consejo como el Tribunal de Cuentas o la Contaduría de Cuentas, o el cargo más apetecido, el de consejero. Pedro de Pomar, Sebastián Siliceo, Andrea Piquinoti, Juan Lucas Doria o Francisco Centani fueron consejeros, llegando incluso a negociar sus condiciones como consejeros dentro de las cláusulas que contenían las condiciones de los asientos negociados.

Así pues, la expansión monetaria continuó no solo con las remesas procedentes de América, sino con la solicitud de crédito. A medida que los bancos recibían dinero procedente de las remesas americanas para su custodia, estos comienzan a realizar préstamos, expandiendo el crédito sin necesidad de tener que depositar en su caja una parte, confiando en la continua entrada de dinero procedente de otros depositantes, los réditos de los préstamos concedidos y la confianza en que no va a haber una retirada de fondos generalizada. Esta actividad supone una notable aceleración de la expansión monetaria, de hecho, como puntualiza el profesor Huerta de Soto:

Si la expansión se realiza simultáneamente por todos los bancos, cada banco puede mantener inalteradas sus reservas de caja, y crear de la nada, con un coeficiente de caja del 0,1, hasta nueve veces sus depósitos iniciales en forma de créditos respaldados por nuevos medios fiduciarios. ${ }^{5}$

${ }^{5}$ J. Huerta de Soto, ob. cit., cap. IV, p. 188. En el presente capítulo, el profesor Huerta de Soto analiza el mecanismo de reserva fraccionaria bajo varios supuestos. 
El hecho de pensar que sobre las cifras aportadas por Pieper o el propio Hamilton habría que multiplicarlas por hasta nueve veces, nos da una magnitud de expansión monetaria realizada por el crédito realmente espectacular. Sirvan de ejemplo las cifras aportadas por Ramón Carande para el reinado de Carlos V, que calcula una introducción de 38.010.226 ducados, o los datos de Felipe Ruiz para el reinado de Felipe II, que estimado un volumen de crédito alrededor de 150 millones de ducados. Todo este enorme volumen de recursos, tanto las remesas procedentes de América como los créditos bancaros, no fueron suficientes para financiar el déficit. La Corona, ante el agobio financiero y las recurrentes suspensiones de pagos, tuvo que recurrir a buscar nuevos ingresos. Con una presión fiscal asfixiante y con escasa capacidad para fijar nuevos impuestos, utilizó una de sus regalías para obtener ingresos, como era la acuñación de dinero. Comenzarían así las alteraciones monetarias.

\section{$\mathrm{V}$ \\ LAS ALTERACIONES MONETARIAS}

La Monarquía Hispánica, en los siglos XVI y XVII, mantenía un sistema monetario formado por monedas de oro y plata, aunque posteriormente se añadió la moneda de cobre con aleación o liga de plata, también conocida como moneda de vellón, es decir, un sistema bimetálico o trimetálico si se tiene en cuenta la moneda de cobre. Cada moneda tenía dos valores de referencia, el intrínseco derivado del valor de la cantidad de metal utilizado en su acuñación, ${ }^{6}$ es decir, del valor de su contenido en oro, plata o cobre, y el valor extrínseco o nominal, establecido por la

En nuestro caso hemos seleccionado uno general, cuando todos los bancos actúan simultáneamente, que era por otra parte la situación propia de los siglos XVI y XVII.

${ }^{6}$ A este respecto señala Mises: «El valor de la moneda lo ha fijado siempre, no la imagen e inscripción que lleva ni la proclamación de las autoridades, sino su contenido metálico. No toda clase de moneda se ha aceptado a primera vista, sino tan solo aquellas clases que poseían una buena reputación por peso y pureza». L. von Mises, ob. cit., p. 38 . 
autoridad monetaria competente, en este caso el Consejo de Hacienda.

La producción de monedas efectivas nacía de un ejercicio de libertad, del encuentro de dos voluntades, por un lado los particulares que vendían a la ceca o casas de moneda el metal precioso para obtener las monedas pagando una cantidad por la gestión (el braceaje y el señoreaje), y por el otro la ceca, que procedía a la amonedación del metal en base a los precios y valores legalmente admitidos. Un aspecto destacable es el número de establecimientos abiertos, y es que en Castilla pero en general en todos los estados europeos se asiste a un progresivo cierre de cecas, conforme el poder estatal se refuerza y su intervención sobre la actividad económica es mayor, el proceso de emisión de moneda era una actividad controlada por el gobierno, en este caso la Corona. En el caso de Castilla, por ejemplo, el número de cecas con licencia para fabricar moneda eran seis, Burgos, La Coruña, Cuenca, Toledo, Sevilla y Segovia, cuya ceca sería fundamental en las emisiones de moneda de vellón. Dentro del proceso de acuñación hay que tener en cuenta los costes de fabricación de las monedas: en primer lugar el del propio metal empleado; en segundo lugar, las cecas debían pagar a sus operarios, para ello recaudaban por sus servicios el braceaje, a lo que habría que añadir el impuesto de señoreaje, el ingreso que obtiene el Rey por esta regalía. Finalmente y en tercer lugar habría que añadir el coste del transporte, pues exigía medios para desplazar las monedas acuñadas y medidas de seguridad. La acuñación de moneda era un derecho exclusivo del soberano, una regalía que permitía modificar el peso, la ley o el valor de las monedas y que como veremos fue utilizada casi siempre con motivos fiscales

Con el inicio del siglo XVII, el delicado equilibrio en el que se sustentaban los sistemas monetarios europeos fue puesto a prueba por las crecientes emisiones de moneda fraccionaria debido al aumento de las necesidades de financiación de los estados, acelerando el aumento de los precios. La política monetaria ejecutada a lo largo de los siglos XVI y XVII solo tenía un fin exclusivamente fiscal. Tanto en el caso de las masivas acuñaciones de moneda de vellón, como en las alteraciones de esta moneda a través de la rebaja de su ley o modificando su valor facial, en todos los casos 
el objetivo de las medidas no era otro que obtener recursos adicionales para financiar el déficit público; en ningún caso se planteó la reactivación económica o el control de los precios, todo quedó supeditado a ofrecer más recursos para la Hacienda Real.

Los grandes periodos de acuñación de vellón en Castilla fueron entre 1602 y 1606, en la monarquía de Felipe III, debido a la necesidad de financiación de las ingentes deudas heredadas de Felipe II, y entre 1618 y 1626 para afrontar el final de la tregua con Holanda y los gastos del inicio de la guerra de los Treinta Años, ya en el reinado de Felipe IV. Debido a las necesidades financieras de la Corona, después de 1626 comenzaron las operaciones de resello de las piezas, que producen beneficios más modestos pero nada despreciables, siendo en 1603, 1636, 1641, 1651, 1654 y 1661 los resellos más significativos.

Las consecuencias de las constantes alteraciones monetarias fueron nefastas para la economía castellana. La abundancia de moneda de vellón aumentaba los precios al ser un numerario con un valor como metal inferior al valor nominal o facial, lo que repercutía negativamente en su aceptación en el comercio o en el crédito. Los vendedores trataban de compensar la reducción de la cantidad de metal contra el que se valoraba con un aumento del precio de los bienes, pero además se generaba un incremento de la velocidad de circulación del dinero de vellón, porque los tenedores de moneda buscaban deshacerse de ella lo más rápidamente posible, acelerando más la subida de los precios.

El intervencionismo del gobierno sobre el dinero tuvo consecuencias desastrosas para la economía. Ante las alteraciones monetarias la ley de Gresham actuó, y tanto el oro como la plata se atesoraron y desaparecieron de la circulación, afectando al circuito comercial, que perdió sus medios de intercambio. Además el proceso inflacionario alteró de tal manera los precios, que los agentes económicos perdieron el mecanismo principal por el cual podían efectuar el ejercicio del cálculo económico. A medida que el gobierno trató de impedir por medio de la coacción legislativa la reacción contraria a sus intereses de los agentes, el mercado reaccionó con la aparición del premio de la plata.

El premio de la plata era el sobreprecio de las monedas de plata respecto a las monedas de vellón, y se convirtió en un termómetro 
que medía la salud del sistema monetario, pues era esta la única manera a través de la cual los castellanos dieron a cada moneda no solo su valor sino también el que le correspondía con relación a las otras. ${ }^{7}$ A medida que las alteraciones monetarias fueron mayores, el premio no dejaba de aumentar. Esta cantidad adicional de moneda de vellón que había que entregar para obtener una moneda de plata provocó en el mercado la aparición de dos precios diferentes para valorar las mercancías, según fuera el pago realizado en moneda de plata o de vellón. El premio también se vio afectado por los defectos del sistema monetario, especialmente su rigidez para adaptarse a los cambios de equivalencias determinadas por el mercado. Además la constante salida de plata al exterior agravó la ya de por sí escasez de moneda de plata, aumentando más el premio (Tabla 2).

Las alteraciones monetarias, al expandir la cantidad de dinero y contribuir a la elevación de los precios, provocaron una alteración de todo el sistema económico, pero esta alteración sería especialmente dañina, pues impactaba directamente sobre el cálculo económico y el ejercicio de la función empresarial. El dinero junto a los intercambios voluntarios permiten que las valoraciones interiores subjetivas e individuales se conviertan en precios de mercado y posibiliten por tanto el cálculo económico y con ello la cooperación social. Además, estas alteraciones repercutieron de manera diferente a cada grupo social. El aumento de los precios no favorecía a los perceptores de rentas, es decir, acreedores en general, arrendadores, rentistas o asalariados, que veían reducidas dichas rentas en términos reales mientras las clases endeudadas, acogían de modo favorable el debilitamiento de la moneda. Las reacciones de la población eran diferentes, la de los campesinos era casi inexistente, mientras que en los estratos más bajos de la población urbana, era violenta y airada. Los trabajadores de los gremios gozaban de mayores privilegios ante las variaciones de precios pero el resto de los asalariados prolongaban sus deudas continuamente esperando que se produjese una depreciación

7 Ante la intervención del gobierno sobre el valor del dinero, el mercado y los miles de individuos que lo conforman reaccionaron valorando la nueva moneda alterada a través del premio de la plata. 
TABLA 2

EVOLUCIÓN DEL PREMIO DE LA PLATA

\begin{tabular}{|c|c|c|c|c|c|}
\hline Año & Premio & $A \tilde{n} o$ & Premio & $A \tilde{n} o$ & Premio \\
\hline 1620 & 104,29 & 1640 & 144,68 & 1660 & 157,81 \\
\hline 1621 & 104,04 & 1641 & 165,75 & 1661 & 165,62 \\
\hline 1622 & 105,64 & 1642 & 224,45 & 1662 & 180,99 \\
\hline 1623 & 110,40 & 1643 & 128,30 & 1663 & 196,87 \\
\hline 1624 & 112,31 & 1644 & 130,09 & 1664 & 207,83 \\
\hline 1625 & 120,44 & 1645 & 132,74 & 1665 & 200,20 \\
\hline 1626 & 148,24 & 1646 & 138,76 & 1666 & 229,67 \\
\hline 1627 & 143,39 & 1647 & 138,08 & 1667 & 242,70 \\
\hline 1628 & 136,29 & 1648 & 141,38 & 1668 & 253,12 \\
\hline 1629 & 116,70 & 1649 & 145,18 & 1669 & 272,91 \\
\hline 1630 & 120,68 & 1650 & 150,69 & 1670 & 275,00 \\
\hline 1631 & 118,67 & 1651 & 153,00 & 1671 & 284,89 \\
\hline 1632 & 118,50 & 1652 & 150,25 & 1672 & 287,50 \\
\hline 1633 & 123,20 & 1653 & 150,00 & 1673 & 287,50 \\
\hline 1634 & 126,30 & 1654 & 150,50 & 1674 & 289,45 \\
\hline 1635 & 126,74 & 1655 & 150,00 & 1675 & 300,52 \\
\hline 1636 & 126,12 & 1656 & 150,00 & 1676 & 308,85 \\
\hline 1637 & 129,13 & 1657 & 156,25 & 1677 & 312,50 \\
\hline 1638 & 134,34 & 1658 & 164,58 & 1678 & 318,75 \\
\hline 1639 & 135,20 & 1659 & 161,98 & 1679 & 331,25 \\
\hline
\end{tabular}

Fuente: Cálculos propios basados en la E.J. Hamilton, ob. cit., Tabla 7, p. 108 promedio de los índices del premio en Andalucía, Castilla La Nueva y Castilla La Vieja.

monetaria. Cuando en Castilla tenía lugar un resello de las monedas de vellón, se producía una avalancha de pagos de deudas, ya que las monedas pasaban a tener el doble o el triple de su valor.

En el caso de la nobleza, el clero y las oligarquías urbanas, la situación era diferente, ya que eran los principales tenedores de las monedas de oro y plata. Ante la situación, procedieron a su atesoramiento, es decir, los tenían encerrados en casa o en manos de banqueros ${ }^{8}$ y hombres de negocios, que los hacían fructificar de manera oportuna, porque la posesión de una cierta cantidad de plata, y no digamos de oro, constituía una inversión cierta y rentable. La Hacienda Real también sufrió las consecuencias de

${ }^{8}$ Es un fenómeno conocido como tesaurización y que es una reacción lógica de la valoración subjetiva que efectúan los individuos ante las nuevas condiciones del mercado, ya que buscan un nuevo bien que garantice el valor; en este caso, será la plata. 
las alteraciones monetarias, ya que las consignaciones y los pagos que ésta efectuaba a los asentistas, juristas y a la burocracia estatal se efectuaban en moneda de plata, sin embargo, el pago de los impuestos se realizaba mayoritariamente en moneda de vellón. A la Monarquía Hispánica no le quedaba otra elección que aceptar los pagos en esta moneda porque con ello estaba respaldando la moneda que emitía.

Conforme la moneda de vellón se acuña con mayor profusión, los arrendadores de impuestos y los tesoreros van a poner cada vez más exigencias para poder abonar en plata la recaudación, perjudicando gravemente a los juristas y librancistas, que eran en definitiva ahorradores, que recibían sus ingresos en moneda de vellón. Al considerable retraso en el pago de los juros y libranzas se unía la moneda, lo que en definitiva era un agravio para los ahorradores, mermando las posibilidades de inversión, y por tanto de crecimiento económico. El mercado de crédito también se vio afectado, puesto que en los contratos de asiento siempre aparecía una cláusula específica que aseguraba la restitución del dinero en una determinada cantidad de piezas de oro y plata. Los préstamos establecidos en plata se podían restituir en vellón siempre y cuando se le añadiese una cantidad suplementaria de moneda fraccionaria o viceversa.

En resumen, las alteraciones en su valoración global suponen la destrucción del sistema monetario, y con ello toda posibilidad de efectuar un cálculo económico viable por los agentes. Además, los agentes en su interrelación dentro del mercado tienen que afrontar una subida de precios consecuencia de las diferentes valoraciones que efectúan los individuos ante el nuevo valor de la moneda. Todo ello se traduce en inflación, lo que distorsiona más la actividad económica y el ejercicio de la función empresarial.

VI

EVIDENCIAS DE LA TACE Y EL PROCESO DE LA DECADENCIA ESPAÑOLA

Existen numerosos estudios sobre las remesas de metales preciosos o del nivel de precios en los siglos XVI y XVII. Cada uno de 
ellos aporta sus criterios y metodologías a la hora de recoger los efectos que tuvieron sobre el nivel de precios la introducción de moneda de plata, el crédito bancario y las alteraciones monetarias. Para estudiar las evidencias que confirmen o apoyen nuestra visión de la Decadencia bajo las premisas de la TACE utilizaremos los datos recogidos en la obra de Earl J. Hamilton El tesoro americano y la revolución de los precios 1501-1650, ya que a pesar de los numerosos estudios posteriores y de las críticas recibidas, la obra de Hamilton sigue siendo insustituible.

Aunque la Escuela Austriaca es bastante reacia a utilizar series de datos o a elaborar cuadros macroeconómicos, mucho más en el caso de economías europeas del siglo XVII cuyos datos están muchas veces incompletos o sesgados, nos sirven de apoyo para confirmar si la Decadencia es una consecuencia directa de la inflación y del intervencionismo sobre la economía de la Monarquía Hispánica. De acuerdo a nuestro planteamiento, estudiaremos tres periodos bien definidos que coinciden con el planteamiento de Hamilton:

- Un periodo de auge inicial comprendido entre 1501 y 1550, que Hamilton denomina como Los comienzos de la Revolución de los Precios.

- A continuación un periodo de comienzo de la crisis entre 1551 y 1600, al que llama Los momentos culminantes de la Revolución de los Precios.

- Finalmente el periodo de crisis y reajuste que coincide plenamente con la Decadencia, que comprendería entre 1601 y 1650 y al que llama Precios durante la inflación del vellón, al poner el foco de atención no solo en las remesas de plata sino también en las alteraciones monetarias o inflación del vellón.

Es evidente que los precios de los bienes experimentaron una subida considerable desde mediados del siglo XVI hasta finales del XVII. La inflación entre 1500 y 1600 fue en gran parte motivada por las importaciones de metales preciosos americanos, causantes del aumento de la cantidad de dinero. Este aumento proporcionó a los grupos de población el acceso a más mercancías para su consumo, dando un impulso al crecimiento de la demanda 
monetaria. A partir de 1600 ese proceso sufrió un impulso al concentrarse junto a las importaciones de metales, las acuñaciones masivas de vellón, las alteraciones en el valor del dinero con los ciclos de inflación/deflación que desarbolaron el sistema monetario, y el intervencionismo del gobierno sobre toda la actividad económica, para tratar de paliar, entre otros muchos, los efectos de la inflación.

\section{Primer periodo 1501-1550: etapa de auge}

El descubrimiento de América y el comienzo de la explotación de las minas de plata marcaron el inicio de las llegadas de remesas de metales preciosos, primero en forma de oro, y después en plata, a medida que la Casa de Contratación y el monopolio comercial establecido controlaron la actividad económica de las Indias. Las cifras de importaciones de metales del periodo, así como de índices de los precios, son las siguientes (Tablas 3 y 4).

A estas cantidades habría que añadir $28.858 .207^{9}$ ducados negociados en asientos, es decir, préstamos bancarios a la Corona, que solicitó Carlos V para financiar su política imperial. Por

\section{TABLA 3}

IMPORTACIONES DECENALES DE ORO Y PLATA (KG.) PERIODO 1503-1550

\begin{tabular}{crr}
\hline Año & \multicolumn{1}{c}{ Plata } & Oro \\
\cline { 3 - 3 } $1503-1510$ & 0 & 4.965 \\
$1511-1520$ & 0 & 9.153 \\
$1521-1530$ & 148 & 4.889 \\
$1531-1540$ & 86.193 & 14.466 \\
$1541-1550$ & 177.573 & 24.957 \\
\hline
\end{tabular}

Fuente: Earl J. Hamilton, El tesoro americano y la revolución de los precios en España 1501-1650, p. 55.

9 Esta cantidad, añadiendo los intereses negociados en los diferentes asientos negociados por la Hacienda, ascendería a 38.010.226 ducados. Véase la obra de Ramón Carande, Carlos V y sus banqueros, pp. 426-427, 463, 505 y 562-563. 
TABLA 4

MEDIAS DECENALES ÍNDICE DE PRECIOS 1501-1550

BASE 1521-1530

\begin{tabular}{|c|c|c|c|c|c|}
\hline Decenios & Andalucía & $\begin{array}{l}\text { Castilla } \\
\text { La Nueva }\end{array}$ & $\begin{array}{l}\text { Castilla } \\
\text { La Vieja }\end{array}$ & Valencia & Media \\
\hline $1501-1510$ & 76,26 & 82,40 & 83,82 & 80,89 & 80,84 \\
\hline 1511-1520 & 74,19 & 81,04 & 81,62 & 89,03 & 81,47 \\
\hline $1521-1530$ & - & 100,12 & 99,93 & 100,51 & 100,19 \\
\hline $1531-1540$ & 121,19 & 109,39 & 102,37 & 105,12 & 109,52 \\
\hline $1541-1550$ & 155,10 & 128,52 & 114,62 & 112,72 & 127,74 \\
\hline
\end{tabular}

Fuente: Earl J. Hamilton, ob. cit., cap. 8, p. 205.

otra parte, es bastante coherente el orden en el que va apareciendo la inflación, comenzando por Andalucía, que era la puerta de entrada de todos los metales preciosos, para llegar a Castilla, centro político del poder donde estaba situada la Corte, lo que de alguna manera establecería un paralelismo con la idea expuesta por Mises al referirse que la creación de dinero y su introducción sobre la economía se hace gradualmente:

Un aumento en la cantidad de dinero de una comunidad significa siempre un aumento en la cantidad de dinero de cierto número de agentes económicos (...) Para estas personas, la relación entre la demanda y la cantidad de dinero se encuentra alterada, ellos tienen un relativo exceso de dinero y una relativa escasez de otros bienes económicos. Ellos expresarán ahora en el mercado su demanda de aquellos bienes que desean más intensamente que antes; están en posición de ofrecer más dinero por las mercancías que desean adquirir. El resultado inmediato de todo esto es que suba el precio de las mercancías afectadas y que disminuya a su vez el valor de cambio objetivo del dinero (...). ${ }^{10}$

10 L. von Mises, La teoría del dinero y del crédito, cap. VIII, pp. 113-114. Mises comenta cómo al introducir dinero sobre ciertos sectores lo único que se hace sobre la economía es incrementar la capacidad de compra de estos agentes y por lo tanto su demanda sobre ciertos bienes, demanda que afecta a su vez a otros agentes que producen o fabrican esos bienes, lo que trae consecuencias sobre la actividad económica a medida que ese dinero se va extendiendo gradualmente sobre los agentes económicos. En nuestro caso el paralelismo es evidente sobre cómo las remesas de plata se van extendiendo por España desde su puerta de entrada a través de la Casa de 
Por lo tanto la subida de los precios comenzó por Andalucía y se extendió gradualmente primero hacia Castilla, después hacia Aragón y finalmente al resto de los reinos españoles. Después de este tránsito, su destino era Alemania y Génova, centros financieros donde se negociaban los asientos.

La llegada de nuevo dinero procedente de América va a provocar un efecto inmediato: un alargamiento artificial de la estructura productiva. Ante estas posibilidades que ofrece el dinero nuevo, los empresarios deciden acometer más proyectos de inversión, ensanchando y alargando las etapas de bienes de capital de la estructura productiva. Comienza a crecer la inversión en el sector de la construcción, patente en el esfuerzo por levantar nuevas barreras defensivas en el Mediterráneo, en fabricar nuevos barcos en los astilleros, en la construcción de nuevas residencias reales como el Palacio de Carlos V en Granada o la residencia de Aranjuez. Todo este proceso impulsa el inicio de un desajuste o descoordinación en el comportamiento de los diferentes agentes económicos. Numerosos proyectos empresariales comienzan a aparecer, muchos vinculados por su carácter privilegiado con la Corona.

Durante este periodo, ante la subida de la población, de la demanda de trabajo y de los salarios, aparece un boom o periodo de gran optimismo exagerado y desproporcionado, que tiene su razón de ser en que los agentes económicos se sienten capaces de ampliar la estructura productiva sin verse forzados paralelamente a sacrificarse minorando su consumo para generar ahorro. Se produce una subida constante de los salarios y de la demanda de trabajadores ante el aumento de las necesidades de contratación de más factores de producción, y esto se refleja en los salarios reales. No solo la Corona dispuso de cuantiosas cantidades de oro y plata, también los particulares, que a través de las lucrativas exportaciones de productos a las nuevas colonias americanas así como por la explotación de los nuevos territorios, o de las nuevas inversiones que hacía la Corona en los sectores naval, de defensa

Contratación en Sevilla hacia Castilla, Aragón, Valencia y Cataluña, para terminar por toda Europa. Su periplo termina en Oriente, donde era intercambiada por sedas, especias y productos de mucho valor, como indica C. Cipolla en su obra La odisea de la plata española, Crítica, Barcelona, 1999. 
o de bienes de lujo, disponían de mayores cantidades de metal para amonedar. Otro indicador que apoya el contraste con la TACE es el crecimiento que experimenta la población y la industria, Valencia, Toledo y Segovia se aprovecharon de este boom a comienzos del siglo XVI, pero a partir de 1550 las condiciones cambiarían. A medida que llegaban más remesas y se solicitaban más créditos, la subida de los precios se hacía más evidente.

\section{Segundo periodo 1551-1600: fin del auge y comienzo de la Decadencia}

La puesta en explotación de las minas de plata de Potosí, Huancavelica y Zacatecas, permitieron a la Corona obtener cuantiosas cantidades de de plata. Además de la remesas, el recurso al crédito por parte de Felipe II continuaba creciendo, de hecho, Felipe Ruiz calcula que Felipe II a lo largo de su reinado tuvo que pedir prestado alrededor de 150 millones de ducados, que sumados a los intereses y gastos la cantidad podría ascender a 180 millones (Tablas 5 y 6).

A pesar de los primeros síntomas evidentes de inflación, el periodo de auge continuaba. La población aumentó de forma significativa en Castilla, en Cataluña y Valencia. Pero el caso especial de Andalucía lo forma la ciudad de Sevilla, no solo porque era la zona agrícola más próspera, sino por ser el centro del comercio y la administración de América. El efecto de la expansión monetaria provocó un auge económico que se traduce en un aumento

TABLA 5

IMPORTACIONES DECENALES DE ORO Y PLATA (KG.) PERIODO 1551-1600

\begin{tabular}{crr}
\hline Año & \multicolumn{1}{c}{ Plata } & \multicolumn{1}{c}{ Oro } \\
\cline { 3 - 3 } \cline { 3 - 3 } $1551-1560$ & 303.121 & 42.620 \\
$1561-1570$ & 942.858 & 11.530 \\
$1571-1580$ & 1.118 .591 & 9.429 \\
$1581-1590$ & 2.103 .027 & 12.101 \\
$1591-1600$ & 2.707 .626 & 19.451 \\
\hline
\end{tabular}

Fuente: Earl J. Hamilton, ob. cit., p. 55. 
TABLA 6

MEDIAS DECENALES ÍNDICE DE PRECIOS 1551-1600

BASE 1571-1580

\begin{tabular}{|c|c|c|c|c|c|}
\hline Decenios & Andalucía & $\begin{array}{l}\text { Castilla } \\
\text { La Nueva }\end{array}$ & $\begin{array}{l}\text { Castilla } \\
\text { La Vieja }\end{array}$ & Valencia & Media \\
\hline $1551-1560$ & 72,85 & 68,21 & 78,74 & 78,06 & 74,47 \\
\hline $1561-1570$ & 92,48 & 89,41 & 92,96 & 87,32 & 90,54 \\
\hline 1571-1580 & 98,24 & 100,00 & 99,44 & 99,83 & 99,38 \\
\hline $1581-1590$ & 110,14 & 110,26 & 105,59 & 111,79 & 109,45 \\
\hline 1591-1600 & 121,26 & 118,77 & 121,78 & 124,28 & 121,52 \\
\hline
\end{tabular}

Fuente: Earl J. Hamilton, ob. cit., cap. 8, p. 215.

de la población, entre 1528 y 1591 este crecimiento fue del 45,5\%, pero es que entre 1530 y 1588 este crecimiento fue del 136\%. No será hasta 1597 cuando Sevilla conozca el declive demográfico.

Uno de los indicadores del efecto que estaba provocando la expansión de la cantidad de dinero sobre la economía fueron las crecientes necesidades de mano de obra, que producen una fuerte inmigración hacia España de numerosos extranjeros, motivada no solo por una mayor demanda de trabajo, sino por salarios más altos. Por otra parte, el alza de los precios agrícolas en el siglo XVI y el consiguiente incremento de las rentas de la tierra convirtieron a la agricultura en muchas regiones en un negocio lucrativo que interesó a los campesinos y a los inversores. En los años finales del siglo XVI había importantes capitales invertidos en censos agrícolas, que se convirtieron en el medio fundamental para conseguir crédito para las tareas agrícolas, pero en realidad eran un sistema para extraer un excedente de los productores rurales para transferirlo al sector privilegiado de la población urbana. Fue un efecto perverso del incremento de la cantidad de dinero, que convirtió un bien de capital básico en una economía de subsistencia como es la tierra en un elemento de especulación financiera. La tierra se convertiría en un elemento de especulación, era una buena inversión para obtener beneficios y prestigio social, por eso fue especialmente atractiva a la nobleza y a los financieros.

A partir de 1550 la elevación de precios destruyó la competitividad de las industrias españolas y por lo tanto facilitó el aban- 
dono de éstas, dando comienzo la crisis. En la debilidad de la clase media y en la falta de una nobleza inversora en actividades productivas se encuentra el perjuicio social contra las actividades comerciales y el trabajo manual. Este fue uno de los efectos que había provocado la llegada de metales, el deseo de vivir de las rentas y no de la actividad productiva. El dinero nuevo también se dirigió a sectores intensivos en el uso de capital y a la inversión en las etapas más alejadas del consumo, es decir, industrias de bienes de capital como eran las atarazanas o astilleros o la construcción. Los proyectos de construcción de instituciones y municipios vivieron un auge, la conservación de edificios, iglesias o murallas, la construcción de palacios reales o residencias de nobles indican que una parte de las remesas de plata se invirtieron así.

La revolución de los precios también afectó a la Mesta y a la ganadería, de hecho el comercio de la lana fue un negocio próspero hasta el año 1550, cuando la subida de precios por encima a la del resto de Europa afectó a su competitividad y provocó un descenso en la venta de lana. Pero otras industrias como la naval o la siderúrgica se vieron afectadas por los elevados costes de los materiales y de la mano de obra debidos a la inflación. El declive tardó en llegar pero a finales del siglo XVI era más que evidente.

\section{Tercer periodo 1601-1650: Crisis y Decadencia}

TABLA 7

IMPORTACIONES DECENALES DE ORO Y PLATA (KG.)

PERIODO 1601-1660

\begin{tabular}{crr}
\hline Año & \multicolumn{1}{c}{ Plata } & Oro \\
\cline { 4 - 4 } \cline { 3 - 3 } $1601-1610$ & 2.213 .631 & 11.764 \\
$1611-1620$ & 2.192 .255 & 8.855 \\
$1621-1630$ & 2.145 .339 & 3.889 \\
$1631-1640$ & 1.396 .759 & 1.240 \\
$1641-1650$ & 1.056 .430 & 1.549 \\
$1651-1660$ & 443.256 & 469 \\
\hline
\end{tabular}

Fuente: Earl J. Hamilton, ob. cit., p. 55. 
TABLA 8

MEDIAS DECENALES ÍNDICE DE PRECIOS 1601-1650

BASE 1621-1630

\begin{tabular}{|c|c|c|c|c|c|}
\hline Decenios & Andalucía & $\begin{array}{l}\text { Castilla } \\
\text { La Nueva }\end{array}$ & $\begin{array}{l}\text { Castilla } \\
\text { La Vieja }\end{array}$ & Valencia & Media \\
\hline $1601-1610$ & 92,34 & 82,96 & 91,23 & 98,07 & 91,15 \\
\hline $1611-1620$ & 84,06 & 84,73 & 84,06 & 96,13 & 87,25 \\
\hline $1621-1630$ & 99,95 & 100,00 & 100,32 & 99,80 & 100,02 \\
\hline $1631-1640$ & 103,16 & 107,08 & 103,85 & 111,63 & 106,43 \\
\hline $1641-1650$ & 125,47 & 115,98 & 114,89 & 112,72 & 117,27 \\
\hline
\end{tabular}

Fuente: Earl J. Hamilton, ob. cit., cap. 8, p. 231.

Las remesas americanas de plata en el periodo comprendido entre 1601 y 1660 fueron un 25,9\% superiores al periodo 1551-1600, sin embargo, la comparación con el periodo 1503-1550 esta magnitud sería cercana al 97,3\%, lo que da una idea del crecimiento que tuvo el dinero nuevo. El recurso al crédito bancario continuó, así en el periodo comprendido entre 1614 y 1621, que coincide con el apogeo de Lerma y el inicio de las hostilidades contra Holanda, se solicitaron asientos por una cantidad superior a 22 millones de ducados. Entre 1622 y 1655 la Hacienda pagó a los hombres de negocios más de 32 millones de ducados de plata por asientos contratados con banqueros de diferentes nacionalidades, lo que da una idea aproximada del volumen de crédito solicitado.

El periodo inicial del reinado los precios subieron debido no solo a las llegadas de plata procedentes de América, sino a las emisiones de vellón. A partir de 1620 empezaron a manifestarse con claridad los efectos de las alteraciones monetarias así, los grandes periodos de acuñación de vellón en Castilla fueron entre 1602 y 1606, y entre 1618 y 1626, pero ante la angustiosa situación financiera, después de 1626 comenzaron las operaciones de resello de las piezas, siendo en 1603, 1636, 1641, 1651, 1654 y 1661 los resellos más significativos. A consecuencia de ello, los precios se incrementaron con fuerza en todas las regiones.

La crisis y la depresión económica se manifiestan por la falta de recursos reales ahorrados para completar unos proyectos de inversión que eran excesivamente ambiciosos. El exceso de inversión en las etapas más alejadas del consumo y la escasez relativa 
de inversión en las industrias más próximas al consumo, unidos a la absoluta falta de ahorro provocada por una presión fiscal asfixiante y al desvío de los escasos fondos hacia inversiones en renta y deuda provocaron una falta de recursos para completar los proyectos de inversión. Se sucedieron las quiebras, las suspensiones de pagos y el despido de trabajadores; la crisis se manifiesta en que se produce a menor ritmo bienes y servicios de consumo, los precios relativos de estos ante la escasez crecen más y tanto la renta nacional como los salarios disminuyen. Además debido a la elevación de los precios, las producciones nacionales perdieron competitividad frente a los mercados exteriores, lo que frenaba una posible salida a través de las exportaciones. Son los efectos de la Decadencia del siglo XVII.

La Decadencia Española del siglo XVII por sus orígenes y su carácter inflacionario y recesivo podría ser considerada como un episodio intenso de stagflation, recesión inflacionaria o estanflación. En efecto, ante la expansión de la oferta monetaria debida a las remesas americanas y al crédito bancario, surgió una depresión económica acompañada de un fuerte crecimiento de los precios de los bienes de consumo, con altas tasas de paro. ${ }^{11}$ La expansión monetaria y la crediticia no es infinita, hay un punto a partir del cual el crecimiento de los precios de los bienes de consumo comienza a ir por delante del aumento de la renta monetaria de los factores originarios, consecuencia de hacer cada vez más capitalintensiva la estructura productiva de la economía. A partir de este momento, los salarios comienzan a reducirse, los empresarios comienzan a sustituir maquinaria por trabajadores y los proyectos de inversión capital-intensivos que se estaban poniendo en marcha entran en dificultades, llegando por fin la inevitable recesión.

11 La estanflación fue más que evidente a finales de los años 70 del pasado siglo, cuando debido a la inflación provocada por la subida de los precios de la energía y el recurso por parte de los gobiernos a las políticas keynesianas para estimular la demanda y el consumo, éstas no solo no reaccionaron al alza, sino que se estancaron. La economía entró en una etapa de crisis o crecimiento casi nulo, que solo las políticas decididamente contrarias a la inflación, al control del gasto público, la rebaja de la presión fiscal y a la reducción del déficit público de comienzos de los 80 pudieron resolver. A este respecto véase de J. Huerta de Soto, Dinero, crédito bancario y ciclos económicos, cap. VI, p. 319. 
La población de las principales ciudades del país, que eran los centros manufactureros y de consumo, experimentó un serio retroceso ante las duras condiciones de vida, la caída del empleo a consecuencia del cierre de las industrias, el retroceso agrario y comercial, y la pérdida de poder adquisitivo que sufrían todos aquellos que dependían de un salario fijo. Toda esta caótica situación afectó a la agricultura y a la industria, con especial virulencia en Andalucía y Castilla. El exceso de reglamentación, la falta de preparación de personal técnico, la escasa tecnología, y la baja calidad de los productos terminaron por arruinar la competitividad del producto frente a los extranjeros. El resto lo hizo el alza de los precios y la descoordinación empresarial provocada por éstos. Sirva de ejemplo la industria textil. En Segovia, si en el momento de mayor auge había 600 telares en 1580, a partir de esta fecha comienza un retroceso considerable, tanto que en 1691 tan solo quedaban 159 funcionando. ${ }^{12}$ A todo ello se une una presión fiscal agobiante, por lo que los comerciantes renunciaban a invertir en la industria textil local y dedicaban todos sus esfuerzos exclusivamente a la exportación de lana, desdeñando la producción nacional. El caso de Córdoba y su industria de paños o la industria de la seda en Granada son similares.

En la agricultura la situación no fue distinta. Los precios de las materias primas experimentaron un aumento singular a partir de 1550. En general el periodo comprendido entre 1502 y 1539 fue relativamente bueno, pero a partir de este año una serie de malas cosechas obligaron al gobierno a recurrir al control de precios, que ya había sido utilizado por los Reyes Católicos. El trigo era el principal producto de consumo para la alimentación de la población, por lo tanto el gobierno de la monarquía debería garantizar su abastecimiento a precios asequibles si no quería que hubiera revueltas. Para ello recurrió a un sistema de intervención basado en un sistema de precios máximos, precios que acentuaron la escasez. Otro efecto del intervencionismo del gobierno sobre la agricultura fue la venta de baldíos. Las tierras baldías suponían un gran beneficio para las poblaciones castellanas, ya que su producción

12 A. García Sanz, Desarrollo y crisis del Antiguo Régimen en Castilla la Vieja, pp. 214-220. 
alimentaba la creciente población e impedía las crisis de subsistencia, sin embargo su situación a mediados del siglo XVI cambió, cuando la tierra aumentó de valor y la Corona, que necesitaba cada vez más recursos, aprovechó la coyuntura para poner a la venta estas tierras. Generalmente estas tierras eran más productivas porque los campesinos, al ejercitar los derechos de propiedad, tenían más incentivos para mejorarlas, hacían un mejor uso de la tierra y realizaban una mayor inversión en capital o tecnología que les permitiese aumentar su productividad. Al efectuar las ventas de tierras, la Corona privó a los agricultores de este medio de producción, alargando la escasez de cereal pero sobre todo, impedía una mayor inversión en capital o tecnología que hiciera más productiva la agricultura.

Las masas silenciosas del siglo XVI tenían pocos portavoces, pero el ejército de vagabundos, mendigos y desempleados que vagaban por los caminos de España de monasterio en monasterio en busca de un plato de sopa, son un testimonio elocuente de hasta dónde habían llegado los efectos de la intervención del gobierno en la economía, y de la Decadencia, como fueron la inflación, la ruptura del sistema comercial y de los elementos básicos para la cooperación, como eran el dinero y los intercambios, una sociedad donde las clases privilegiadas monopolizaban la riqueza y el gobierno intervenía en la economía sin control alguno.

\section{VII}

\section{EL INTERVENCIONISMO ECONÓMICO DE LA MONARQUÍA HISPÁNICA}

El análisis de los ciclos económicos señala que gran parte de las crisis financieras y sus posteriores consecuencias sobre la economía real son precedidas por una política monetaria inadecuada. En el caso español, la crisis del siglo XVII, conocida como Decadencia Española, evidencia a los ojos de la TACE, cómo la introducción de grandes cantidades de dinero nuevo o creado, el recurso al crédito bancario y las alteraciones monetarias realizadas, que fueron en su conjunto medidas de política monetaria de la Monarquía Hispánica, provocaron la reacción lógica del mercado, 
elevando las tasas de inflación de tal manera que afectaron negativamente a los agentes económicos, impidiendo el cálculo económico al destruir el dinero y las relaciones de intercambio, e interviniendo en la economía sobre la libertad de los individuos para ejercer la función empresarial.

Charles P. Kindleberger en su obra Manías, pánicos y cracks $^{13}$ sostiene acertadamente que las expansiones monetarias y crediticias ejercieron un papel fundamental en cada una de las crisis financieras que acontecieron antes del siglo XVIII. En este sentido, la Decadencia Española es un proceso de reajuste económico que tuvo un efecto inmediato: una intensa y continuada alza de los precios. Además el problema se agravó cuando la monarquía absoluta intervino en prácticamente todas las parcelas de la actividad económica:

- Creó monopolios que impedían el libre ejercicio de la función empresarial, favoreciendo a unos gremios que imponían unas normas y reglamentaciones muy estrictas, limitaban la producción y establecían por lo tanto unas barreras de entrada que alejaban a nuevos empresarios y a cualquier atisbo de competencia.

- Alteró el valor del dinero para obtener recursos adicionales para financiar su déficit público. El resultado no solo fue acelerar el alza de los precios, sino que desarticuló la institución social por excelencia como es el dinero.

- Monopolizó el comercio entre los países y entre los particulares, en unos casos impidiendo el comercio a las naciones europeas con las colonias americanas, y en otros limitando las posibilidades comerciales a los individuos al monopolizar gran parte de los sectores económicos.

- Alteró los derechos de propiedad de diversas maneras, como las incautaciones que se efectuaron en numerosas ocasiones de las remesas de plata de los particulares, por medio de la venta de las tierras de los baldíos, con las incautaciones de buques para dedicarlos a la defensa nacional, pero sobre todo con las

13 C.P. Kindleberger, Manías, pánicos y cracks, historia de las crisis financieras, Ariel, Madrid, 2.012. 
declaraciones de quiebras, ya que rompían la garantía que ofrecía el monarca de que iba a ser capaz de resarcir sus deudas, lo que generaba una enorme desconfianza en el sistema económico y financiero.

- Impuso una presión fiscal confiscatoria para obtener recursos de donde sea y a costa de quien sea. El sistema fiscal era injusto al recaer la carga sobre las clases más desfavorecidas, pero además tenía un sistema de administración y recaudación muy deficiente. La elevación de alcabalas, tercias, la fijación de estancos, los subsidios, el servicio de millones, toda la enorme cantidad de figuras fiscales que impuso la monarquía destruyeron el ahorro privado, que es la base sobre la que se sustenta el crecimiento económico, limitaron la capacidad de consumo de la población y favorecieron la extensión de la pobreza sobre amplias capas de la población.

- Trató de limitar las consecuencias de su desastrosa política monetaria y fiscal mediante la fijación de precios máximos por medio de decretos y leyes. La consecuencia de todo ello fue una mayor escasez de bienes y una mayor elevación de los precios, justo lo contrario de lo que pretendía el gobierno al aplicar estas medidas.

El intervencionismo de la Monarquía Hispánica se podría asimilar al socialismo. Hayek en su obra La Fatal Arrogancia ${ }^{14}$ considera que el socialismo es un error intelectual o de arrogancia científica porque pretende diseñar y organizar total o parcialmente mediante medidas coactivas el entramado de relaciones humanas que constituyen el mercado y la sociedad. Según Hayek, la sociedad no es un sistema racionalmente organizado por ninguna mente o mentes sino que es un orden espontáneo, un proceso en constante evolución resultado de la interacción de millones de individuos que no ha sido deliberadamente diseñado por nadie. La capacidad innata del ser humano le hace concebir nuevos fines constantemente, dedicando su esfuerzo e inteligencia

14 F. von Hayek, La fatal arrogancia, los errores del socialismo, Unión Editorial, Madrid, 1990. 
a descubrir y elaborar los medios necesarios para alcanzarlos, pero este proceso exige libertad económica e individual.

Siguiendo este argumento expuesto por Hayek, la Monarquía Absoluta española de los siglos XVI y XVII se puede asimilar con el socialismo por varias causas:

- Utiliza al igual que el socialismo la coacción institucional porque pretende mejorar u organizar determinadas parcelas de la vida económica o social, careciendo para ello del enorme volumen de información práctica y dispersa y de su capacidad para entenderla.

- Empleo de la coacción e incluso de la violencia que impide a los ciudadanos libremente buscar y perseguir sus fines.

- Un intervencionismo feroz sobre el libre ejercicio de la libertad económica e individual a través de una insoportable presión fiscal que extrae las rentas de los individuos, unas restricciones a la producción y el comercio a través de una política proteccionista, y a la intervención sobre los precios, que alteran el puente que permite convertir el valor subjetivo psíquico interior en precios de mercado, a través de la intervención sobre las dos instituciones que lo hacen posible, el dinero y los intercambios voluntarios.

De la misma manera que Mises y Hayek demostraron la imposibilidad del cálculo económico socialista, el intervencionismo de la monarquía absoluta sobre la economía y la sociedad explican la profunda y grave crisis económica que sufrió España en el siglo XVII.

VIII

LA SALIDA DE LA CRISIS:

AUSTERIDAD Y REFORMA ECONÓMICA

A partir de 1680, en pleno reinado de Carlos II, una serie de gobiernos realizaron una ambiciosa política de reformas monetarias y fiscales cuyos efectos inmediatos fueron devastadores para la economía nacional, pero que sentaron con firmeza las bases para 
la posterior recuperación del siglo XVIII. Básicamente estas reformas consistirían en:

- El reajuste de la moneda de vellón, mediante la deflación de 1680 , y el posterior ajuste con la moneda de plata y oro, efectuado en 1686. Ello permitió el saneamiento del sistema monetario.

- La reducción de las solicitudes de crédito bancario y la puesta en orden de las finanzas reales, reconociendo las deudas pendientes de cobro y estableciendo un límite a las mismas. La política de saneamiento monetario y fiscal trataba de recuperar de nuevo la confianza de los hombres de negocios.

- Reducción de la presión fiscal, eliminando impuestos indirectos, revisando el valor de los encabezamientos y proponiendo medidas para mejorar la eficacia en la recaudación de los impuestos.

- Al reducir la presión fiscal había que reducir y controlar el gasto público. Para ello, se efectuaron recortes en los intereses de la deuda pública, se controló el gasto que efectuaba la Casa Real y la burocracia estatal, y por primera vez se fijó un presupuesto con unos objetivos de ingresos y sobre todo de gasto. También se establecerían medidas para controlar el fraude fiscal.

- Se planteó una reforma de la administración, reduciendo el número de funcionarios de los consejos de gobierno, suprimiendo los privilegios e imponiendo un control más estricto sobre el desempeño de cada puesto. Se trató con especial virulencia de eliminar los oficios acrecentados, esto es, los puestos creados expresamente por el gobierno para venderlos y obtener así ingresos adicionales.

- Se procedió a una tibia desregulacion de la economía suprimiendo normas establecidas por los gremios, sobre todo las referentes a la calidad y producción.

- Se intentó estimular el comercio, especialmente a través de una institución creada a tal fin, como fue la Junta Comercio. En ella se aplicaron medidas como la supresión de impuestos a los nuevos establecimientos o la adquisición de técnicos y maquinaria en el extranjero, con el fin de restablecer las industrias y favorecer las exportaciones de manufacturas. 
Tras el auge del siglo XVI llegó la crisis del siglo XVII. Merece la pena, a modo de conclusión, la siguiente cita de Mises:

El auge empobrece. Pero los quebrantos morales que ocasiona son aun más graves que los perjuicios materiales. La gente pierde la fe en sí misma y desconfía de todo. Cuanto mayor fue primero su optimismo, tanto más honda es luego la desesperanza y la frustración. ${ }^{15}$

\section{REFERENCIAS BIBLIOGRÁFICAS}

Acemoglu, A. (2013): Porqué fracasan los países, Madrid, Deusto Ediciones.

AKERMAN, J. (1932): Economic progress and economic crises.

Álvarez Nogal, C. (1999): El Factor General del Rey y las finanzas de la Monarquía Hispánica, Dpto. Historia Económica Universidad Carlos III, Madrid.

- (2000): El dilema monetario de la monarquía española en el siglo XVII. ¿Pequeñas monedas de plata o crédito internacional? Universidad Carlos III.

- (2000): El transporte de moneda en la España del siglo XVII: mecanismos y costes. Dpto. Historia Económica Universidad Carlos III.

- (2000): La moneda de vellón y su influencia en la negociación del crédito en la monarquía durante el siglo XVII. Dpto. Historia Económica Universidad Carlos III.

Artola, M. (1982): La Hacienda del Antiguo Régimen, Alianza Editorial, Madrid.

Asthon, R. (1965): Crisis in Europe 1560-1660.

BÖHM-BAWERK, E. (1947): Capital e interés, Fondo Cultura Económica.

CARANDE, R. (2000): Carlos V y sus banqueros, Editorial Crítica, Madrid.

Castillo Pindado, A. (1963): «Los juros apogeo y fin de un instrumento de crédito», Revista Hispania, n.. 89. 
Chamberlain, J. (1914): El atraso de España, F. Sempere editores, Valencia.

Cipolla, C. (1994): El gobierno de la moneda. Ensayos de historia monetaria, Crítica, Barcelona, 1994.

- (1999): La odisea de la plata española, Editorial Crítica, Barcelona.

de Carlos Morales, C. (2008): Felipe II: el Imperio en bancarrota, Ediciones Dilema.

de Santiago, J. (2000): Política monetaria en Castilla durante el siglo XVII, Junta de Castilla y León, Valladolid.

Domínguez Ortiz, A. (1946): Orto y ocaso de Sevilla. Estudio sobre la prosperidad y decadencia de la ciudad durante los siglos XVI y XVII, Sevilla.

- (1969): «Las remesas de metales preciosos de Indias en 16211665» en Anuario de Historia Económica y Social II.

- (1983): Politica y Hacienda de Felipe IV, Madrid.

- (1984): Política fiscal y cambio social en la España del siglo XVII, Instituto de Estudios Fiscales.

- (1996): Los extranjeros en la vida española durante el siglo XVII, Diputación Provincial de Sevilla.

EKELUND, R.B. \& HeRbeRT, R.F. (2011): Historia de la Teoría Económica y de su método, MCGraw-Hill.

Font DE VillanueVa, C. (2008): La estabilización monetaria de 16801686. Pensamiento y política económica, Servicio estudios Banco de España, n.ำ 52.

García Cuenca Ariati, T. (1982): El Consejo de Hacienda 1476-1803, Madrid.

García Guerra, E. (2003): Moneda y arbitrios. Consideraciones del siglo XVII, CSIC, Madrid.

García SANZ, A. (1977): Desarrollo y crisis del Antiguo Régimen en Castilla La Vieja. Economía y sociedad den tierras de Segovia 15001814. Akal, Madrid.

Gutierrez Nieto, J.I. (1982): El pensamiento económico y social de los arbitristas. Historia Menéndez Pidal, Tomo XXVI, Madrid. Hamilton, E.J. (1988): Guerra y precios 1650-1800, Alianza Editorial, Madrid.

- (2000): El tesoro americano y la revolución de los precios 1501-1640, Editorial Crítica, Barcelona. 
HAYEK, F. (1936): La teoría monetaria y el ciclo económico, Espasa Calpe, Madrid.

- (1990): La fatal arrogancia, los errores del socialismo, Unión Editorial, Madrid.

- (1997): Precios y producción, una explicación de la crisis de las economías capitalistas, Ediciones Aosta.

- (2000): Ensayos de teoría monetaria, Unión Editorial, Madrid.

- (2003): La contrarrevolución de la ciencia. Estudios sobre el abuso de la razón, Unión Editorial, Madrid.

- (2008): Los fundamentos de la libertad, Unión Editorial, Madrid.

- (2011): El orden sensorial, Unión Editorial, Madrid.

HeCKSCHER, E. (1943): La época mercantilista. Fondo de Cultura Económica.

HiLL, C. (2002): The century of revolution, Routledge.

Huerta De Soto, J. (2002): Estudios de economía política, Unión Editorial, Madrid.

- (2011): Dinero, crédito bancario y ciclos económicos, Unión Editorial, Madrid.

- (2011): Socialismo, cálculo económico y función empresarial, Unión Editorial, Madrid.

- (2012): La Escuela Austriaca: mercado y creatividad empresarial, editorial Síntesis.

Kindleberger, C. (2011): Historia Financiera de Europa, Editorial Crítica.

- (2012): Manías, pánicos y cracks, historia de las crisis financieras, Ariel, Madrid.

Menger, C. (2006): El método de las ciencias sociales, Unión Editorial, Madrid.

- (2013): El dinero, Unión Editorial, Madrid.

Mises, L. (2001): Crítica del intervencionismo, Unión Editorial, Madrid.

- (2004): La acción humana, Unión Editorial, Madrid.

- (2005): Burocracia, Unión Editorial, Madrid.

- (2011): Teoría e Historia, Unión Editorial, Madrid.

- (2012): Tratado del dinero y del crédito, Unión Editorial, Madrid.

Mitchell, W.C. (1927): Business Cycles, the problem and Its Setting, New York. 
Perdices de Blas, L. (1998): El mercantilismo: política económica y estado Nacional, Madrid.

Pieper, R. (1987): La Revolución de los precios en España: sus causas y sus efectos, Barcelona.

Ravier, A. (2011): La Escuela Austriaca desde dentro, Volúmenes I y II, Unión Editorial, Madrid.

RothbARD, M.N. (2011): Historia del pensamiento económico, Unión Editorial, Madrid.

SAnZ Ayán, C. (1988): Los banqueros de Carlos II, Universidad de Valladolid.

- (2013): Los banqueros y la crisis de la Monarquía Hispánica de 1640, Editorial Marcial Pons.

Schumpeter, J.A. (2009): Historia del pensamiento económico, Ariel.

STRANDLING, R.A. (1983): Europa y el declive de la estructura imperial española 1580-1720, Ediciones Cátedra.

Trevor Davies, R. (1972): La decadencia española 1621-1700, Editorial Labor, Barcelona.

VILAR, P. (1964): Crecimiento y desarrollo. Economía e historia. Reflexiones sobre el caso español, Barcelona.

- (1981): Oro y moneda en la historia 1450-1920, Editorial Ariel, Barcelona.

VV.AA. (1997): El capitalismo y los historiadores, Unión Editorial, Madrid.

WICKSELL, K. (2000): Interés monetario y precios de los bienes, Ediciones Aosta, Madrid. 
